\title{
A Life Span Study of Exploratory Eye Movements in Healthy Subjects: Gender Differences and Affective Influences
}

\author{
SACHIKO NISHIURA, YOUKO NAKASHIMA*, KEIICHIRO MORI, TAKAYUKI KODAMA*, \\ SATOSHI HIRAI*, TAKATSUGU KURAKAKE* CHIYOMI EGAMI** \\ AND KIICHIRO MORITA* \\ Department of Neuropsychiatry, Kurume University School of Medicine, *Cognitive and \\ Molecular Research Institute of Brain Diseases and ** Department of Pediatrics and \\ Child Health, Kurume University School of Medicine, Kurume 830-0011, Japan \\ Received 18 April 2007, accepted 30 November 2007 \\ Edited by RYOJI YAMAKAWA
}

\begin{abstract}
Summary: To evaluate age and gender differences as well as effects of affection, we examined exploratory eye movements. Exploratory eye movements were recorded in healthy subjects (57 women and 57 men) ranging from 9 to 74 years. All subjects were divided into three groups as pre puberty, young, and older adults to study the influences of age and gonadal hormones. Exploratory eye movements were analyzed for total eye scanning length (TESL), and total numbers of gaze points (TNGP) as subjects viewed neutral or affectively charged pictures. TESL and TNGP in older adults were significantly larger than that in both pre puberty and young adults for crying babies. TESL and TNGP in pre puberty were significantly smaller than that in both young and older adults for circles. TESL and TNGP in pre puberty were significantly smaller than that in older adults for smiling babies. Pre puberty and young adult of both genders for crying babies showed significantly shorter TESL than for when smiling babies. When viewing circles, young adult women had shorter TESL than men. TNGP in young adult women was smaller than in men for circles or crying babies. TNGP of young adult women in the visual right field was significantly smaller than in men. TNGP for crying babies was significantly smaller than that for smiling babies in young adults of both genders for the left field. Exploratory eye movements thus are a useful marker of visual cognitive function. Gender differences were limited to younger adults, suggesting influences of gonadal hormones.
\end{abstract}

Key words exploratory eye movements, gender difference, affective stimuli, laterality, visual cognition

\section{INTRODUCTION}

Eye movements have attracted attention as biologic markers. For example, patients with psychiatric disorders such as schizophrenia or affection have been compared with healthy subjects [1-3]. Holzman et al. [1] reported that schizophrenic patients have less global accuracy smooth pursuit and lower pursuit gain than normal control subjects.

In studies of exploratory eye movements, subjects are examined with an eye-mark recorder as they view several pictures while the points of gaze are analyzed in terms of several elements [3]. This assessment method, considered to reflect abnormalities of eye movements and visual information processing in natural settings, is a useful psycho-physiological marker of visual cognitive function that first requires extensive evaluation in healthy controls, concerning age and gender differences $[4,5]$. The authors suggested that exploratory eye movements in young adult women have been demonstrated to have a more limited eye movement range, with longer maintenance of gaze in

Corresponding author: Kiichiro Morita, Cognitive and Molecular Research Institute of Brain Diseases, Kurume University, 67 Asahi-machi, Kurume 8300011, Japan. Tel: 0942-31-7581 Fax: 0942-31-7911 E-mail: kiichiro@med.kurume-u.ac.jp 
a given direction, than men of similar age, suggesting a possible gonadal hormonal influences $[4,5]$. One reason why such analyses are important involves, reported gender differences in aspects of brain function. Men have been found perform better than women in certain spatial, motor [6-8], and language tasks [9] as well as in scanning the visual field [10]. Gender differences in event related potentials (ERPs) concerning visual information processing have been reported [1113] and also might involve gonadal hormones $[6,14,15]$.

Affect and the following emotion are basically important between human relationships in human life events. Because, a negative affection as cry, fear should obstruct life events, however, a positive affection as pleasure, happy should facilitate of life behavior. The effects of affective stimuli have been reported in event-related potentials, especially P300 components $[13,16]$. Those authors reported the P300 amplitude was larger for the negative affection as angry or sad than that for the positive affection as pleasure or neutral stimuli and suggested that event-related potentials was useful biological marker to evaluate the effects of affection. Thus, it is important to study the effects of affections on the cognitive function for exploratory eye movements as one of the biological marker. Indeed, the exploratory eye movement was inhibited in depressive patients [17], because of depressive emotion.

The present study was performed to examine whether gender differences of exploratory eye movements were observed or not, during the three life phases as the pre puberty (children), puberty (young adult) and post puberty (elder adults) of the healthy, and the affective stimuli (smiling and crying babies). The second aim of the present study was, whether or not there is any gender and/or age difference for affective stimulus.

\section{MATERIALS AND METHODS}

\section{Subjects}

A group of 114 healthy paid volunteers (9 to 74 years) (mean age $\pm \mathrm{SD}, 35.9 \pm 19.3$ years). All subjects were divided into three groups as pre puberty (12 boys and 12 girls: $10.2 \pm 0.9$ and $10.5 \pm 1.4$, respective1y), young adults ( 27 men and 27 women: $30.5 \pm 6.5$ and $30.3 \pm 7.2$, respectively), and older adults (post puberty) (18 men and 18 women: $59.5 \pm 6.3$ and $60.9 \pm 8.6$, respectively). No significant age differences were observed in each life phase. Women were not recorded at any particular time during the menstrual periods. All subjects were right handed, had normal vision, and had no history of psychiatric or neurological diseases or drug addiction. All subjects gave written informed consent for study participation. The ethics Committee of Kurume University approved the present study.

\section{Eye mark recording}

Eye movements were recorded using an eye mark recorder (Nac, EMR-8, Tokyo, Japan) that consisted of two video cameras (left- and right-eye mark-shooting units) fixed to the left and right sides of a headband and another camera (field-shooting unit) fixed to the top of a helmet. Infrared light $(850 \mathrm{nM})$ sources were positioned in front of each lower eyelid. The side cameras recorded the infrared light reflected from the cornea of the eye. The camera on the top of the cap recorded the pictures shown on the screen. After a camera controller superimposed these three recordings with a $0.01 \mathrm{sec}$ electronic timer, the combined recording was saved on videotape. Movement of more than $1^{\circ}$ with duration greater than $0.1 \mathrm{sec}$ was scored as an eye movement. Accordingly, the gazing point was determined from a gazing time exceeding $0.1 \mathrm{sec}$. This technique enabled us to determine eye fixation points. Recorded data were assessed by a computer analysis system. In the present study, exploratory eye movements were analyzed for two parameters: total eye scanning length (TESL) for gazing points, total number of gazing points (TNGP) as reported before $[2,4]$. Furthermore, in the present study, we divided the measures as TNGP to the right half and the left half field of the screen as the total number of gazing points of the left field (TNGP-1) and the right field (TNGP-r) of screen, and counted the total number of transferring between the left and the right fields. Eye scanning length was calculated from the distance between two eye gazing points as reported previously $[2,4]$.

\section{Eye movement recording procedure}

In a darkened room where visual and auditoria sensory stimuli were attenuated, eye movement was recorded using the eye-mark recorder. Before eye movements were recorded, subjects were instructed to confirm each subsequently viewed picture exactly as presented. All subjects were also instructed to view and fix several corners' points to check their eye movements to evaluate neurological deficits and low-level eye movement as reflex organic saccade. All subjects have no deficits in the present procedure. Exploratory eye movements and fixation points during perception of pictures were examined. The pictures were project- 
ed onto a screen to form images $120 \mathrm{~cm}$ wide and 90 $\mathrm{cm}$ tall. Maximum angles of sight lines were $40^{\circ}$ horizontally and $24^{\circ}$ vertically. Each block consisted of a series of three pictures each presented for $15 \mathrm{sec}$.

Three kinds of pictures were used as shown in Fig. 1. The picture of steps on: two symmetrical smiling babies with smiling sound (70 dB, SPL) examining possible emotional influences. Picture of steps at center: Two symmetrical crying babies with crying sound (70 dB, SPL) examining possible emotional influences. The picture of steps below: two symmetrical simple circles to examine drive and motivation in subjects.

The crying babies and the smiling babies were counterbalanced. The recording was done as follows. At session 1: all subjects were asked, "Look the front pictures freely." (free condition). At session 2: all subjects were asked "Look the front picture carefully and memorize" because "I will ask you immediately after recording, what picture did you see?" (memorized condition). At session 3: all subjects were asked, "Are there any differences between the present picture and the former one?" to test confidence and attention (confidence condition). Data were analyzed from the right eye and the left eye in the present study. There was no significant difference of analyzing elements in the eye movements between the right and left eyes.

\section{Statistical analysis}

In the present study, we used the data only obtained from the confidence condition (session 3), because the confidence condition was mostly reflecting the visual cognitive function [2]. For data, one-way repeated analysis of variance (ANOVA) was performed to determine epsilon factors using $\mathrm{G}$ to $\mathrm{G}$ and
$\mathrm{H}$ to $\mathrm{F}$ epsilon. A two-way (gender $\times$ stimuli or gender $\times$ field) ANOVA was used to compute the main gender and the main stimuli and the field effects in each life period (childhood, young adulthood and older adulthood). Whether interaction was obtained or not, one-way ANOVA was used. A one-way ANOVA (gender, stimulus, field) was used to compute the main gender, group, stimulus and field effects Post-hoc analyses were conducted using Scheffe tests. A level of $p<0.05$ was accepted as statistically significant.

\section{RESULTS}

Typical sequences of the exploratory eye movements for one healthy adult men and women viewing three pictures are shown in Fig. 1. The subject showed

Gaze points in typical series : Confidence condition

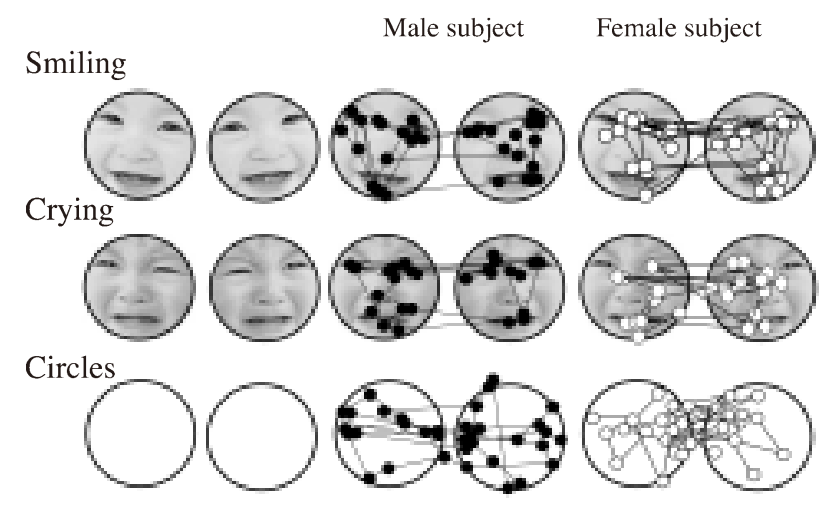

Fig. 1. Three pictures used (left) and typical series of exploratory eye movements in a young adult man (middle) and woman (right). Each dot indicates a gaze point and each line, a movement. The gaze points were located centrally in simple circles, especially in woman.

TABLE 1 .

Exploratory eye movements in confidence condition

\begin{tabular}{clccc}
\hline & & Pre-puberty & Young adult & Older adult \\
\hline \multirow{2}{*}{ TESL $(\mathrm{cm})$} & Smiling & $518.2 \pm 164.7$ & $566.0 \pm 156.7$ & $607.0 \pm 107.0$ \\
Female & Crying & $422.5 \pm 162.7$ & $452.7 \pm 153.7$ & $560.0 \pm 167.5$ \\
& Circles & $424.0 \pm 144.1$ & $458.3 \pm 132.6$ & $556.3 \pm 164.3$ \\
\hline \multirow{2}{*}{ Male } & Smiling & $534.7 \pm 167.6$ & $592.2 \pm 116.7$ & $603.7 \pm 114.7$ \\
& Crying & $430.5 \pm 153.4$ & $474.2 \pm 161.2$ & $536.9 \pm 157.8$ \\
& Circles & $417.0 \pm 120.8$ & $569.4 \pm 134.0$ & $567.4 \pm 198.3$ \\
\hline \multirow{2}{*}{ TNGP $(\mathrm{n})$} & Smiling & $26.6 \pm 3.4$ & $27.8 \pm 5.2$ & $29.3 \pm 4.7$ \\
Female & Crying & $25.4 \pm 3.8$ & $23.6 \pm 5.6$ & $27.0 \pm 5.7$ \\
& Circles & $23.5 \pm 2.5$ & $24.6 \pm 5.6$ & $27.1 \pm 6.8$ \\
\hline \multirow{2}{*}{ Male } & Smiling & $27.1 \pm 5.1$ & $28.8 \pm 5.3$ & $28.6 \pm 3.7$ \\
& Crying & $23.4 \pm 3.4$ & $26.3 \pm 6.9$ & $27.3 \pm 4.3$ \\
& Circles & $24.3 \pm 5.1$ & $28.9 \pm 5.0$ & $26.5 \pm 4.8$ \\
\hline
\end{tabular}

TESL, total eye scanning length; TNGP, total number of gaze points. 
clear eye movements, which attached to left and right baby's eyes and mouth. The gazing points tended to expand in pictures, smiling and circles but not in crying pictures (Fig. 1, Table 1).

\section{Total eye scanning length (TESL) (Figs 2, 3)}

Pre puberty: The main gender difference by two-way ANOVA (gender $\times$ stimuli) was not significant, but the main stimulus difference was significant $[\mathrm{F}=6.9$, $\mathrm{p}<0.01]$. There was no interaction observed between gender and stimuli. The TESL when viewing smiling babies was significantly longer than that of both the
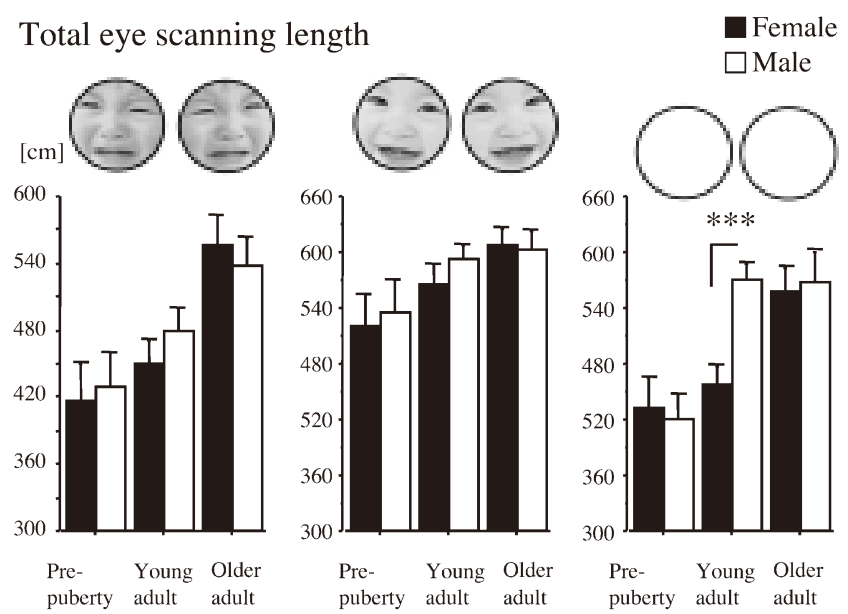

Fig. 2. Total eye scanning length (TESL; ordinate) was plotted against groups and stimuli (abscissa). TESL was clearly prolonged when men viewed the circles. Asterisks indicate significant differences between women and the men. ***: $\mathrm{p}<0.001$

Total eye scanning length

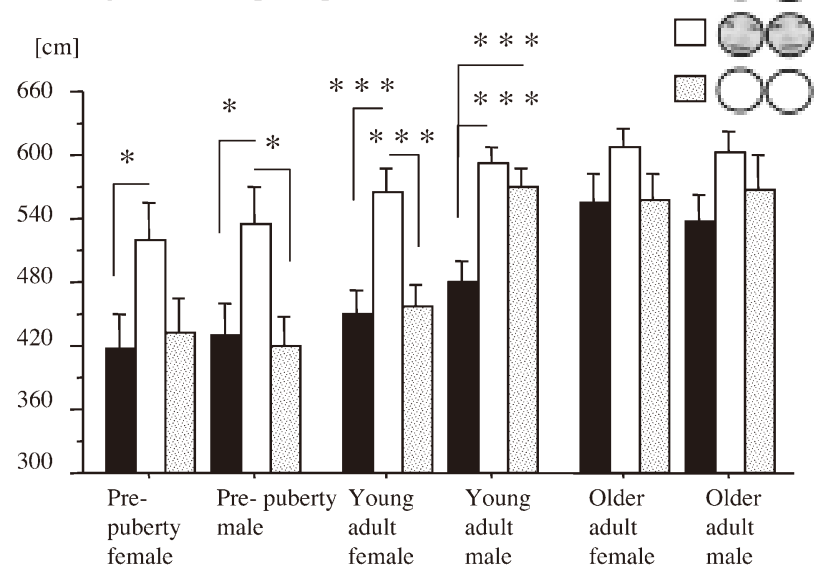

Fig. 3. Total eye scanning length (TESL; ordinate) at each session in three age groups (abscissa). Asterisks indicate significant differences between stimuli. $*: \mathrm{p}<0.05$, $* * *: \mathrm{p}<0.001$ crying babies $(\mathrm{p}<0.01)$ and the circles $(\mathrm{p}<0.01)$. There were no gender differences observed by one-way ANOVA (gender). In girls, TESL $[\mathrm{F}=3.0, \mathrm{p}<0.05]$ when viewing crying babies was significantly shorter $(\mathrm{p}<0.05)$ than those in smiling babies. In boys, TESL $[\mathrm{F}=4.3, \mathrm{p}<0.05]$ when viewing crying babies was significantly shorter than those in smiling babies $(\mathrm{p}<0.05)$ and the circles $(\mathrm{p}<0.05)$.

Young adult: The main gender difference by two-way ANOVA (gender $\times$ stimuli) was significant $[\mathrm{F}=11.9$, $\mathrm{p}<0.0001]$, and the main stimulus difference was also significant $[\mathrm{F}=17.0, \mathrm{p}<0.0001]$. There was interaction observed between gender and stimuli $(\mathrm{p}<0.05)$. The TESL when viewing smiling babies was significantly longer than that of both the crying babies $(\mathrm{p}<0.0001)$ and the circles $(\mathrm{p}<0.01)$. By one-way ANOVA (gender), TESL of women when viewing the circles was significantly shorter $[\mathrm{F}=18.1, \mathrm{p}<0.0001]$ than that of age-matched men. In women, TESL $[\mathrm{F}=10.4$, $\mathrm{p}<0.0001]$ when viewing smiling babies was significantly longer than those for the crying babies $(\mathrm{p}<0.001)$ and the circles $(\mathrm{p}<0.001)$. In men, TESL $[\mathrm{F}=9.9$, $\mathrm{p}<0.0001]$ when viewing smiling babies was significantly longer than those in crying babies $(p<0.001)$ and TESL when viewing the circles was significantly longer than those in crying babies $(\mathrm{p}<0.01)$.

Older adult: The main gender difference by two-way ANOVA (gender $\times$ stimuli) was not significant, and the main stimulus difference was also not significant. There was no interaction observed between gender and stimuli $(\mathrm{p}=0.058)$. There were no gender differences observed by one-way ANOVA (gender). There was also no significant stimulus difference in elder women or men.

\section{Total number of gazing points (Fig. 4)}

Pre puberty: By two-way ANOVA, the main gender difference was not significant, but the main stimuli difference was significant $[\mathrm{F}=10.5, \mathrm{p}<0.0001]$. There was no interaction observed between stimuli and gender. The TNGP for simple circles of smiling babies was significantly larger than those of both the crying babies $(\mathrm{p}<0.001)$ and the circles $(\mathrm{p}<0.01)$.

Young adult: The main gender difference by two-way ANOVA was significant $[\mathrm{F}=17.7, \mathrm{p}<0.0001]$ and the main stimuli difference was also significant $[\mathrm{F}=9.1$, $\mathrm{p}<0.0001]$. There was no interaction observed between stimuli and gender. By one-way ANOVA (stimuli), in women, TNGP of smiling babies was significantly larger than those of the crying babies $(\mathrm{p}<0.001)$. But, in men, there were not significant differences observed among three stimuli. By one-way ANOVA 
(gender), TNGP of women when viewing the crying babies was significantly smaller than those of agematched men $[\mathrm{F}=5.0, \mathrm{p}<0.05]$. By one-way ANOVA, TNGP of women when viewing the circles was significantly smaller than those of age-matched men $[\mathrm{F}=16.5, \mathrm{p}<0.0001]$.

Older adult: The main stimuli difference by two-way ANOVA was significant, $[\mathrm{F}=3.8, \mathrm{p}<0.05]$ and the main gender difference was not significant. There was no interaction observed between stimuli and gender. The TNGP of smiling babies was significantly larger than those of the circles $(\mathrm{p}<0.05)$.

\section{Total number of transferring (between left and right fields)}

Pre puberty: The main gender difference by two-way ANOVA (gender $\times$ stimuli) was not significant, but the main stimulus effect was significant $[\mathrm{F}=8.9$, $\mathrm{p}<0.001]$. There was no interaction. The number of transferring of the smiling babies was significantly larger than that of both the crying babies $(\mathrm{p}<0.0001)$ and the circles $(\mathrm{p}<0.01)$. By one-way ANOVA (stimuli), the number of transferring of girls when viewing smiling babies was significantly larger $[\mathrm{F}=5.3, \mathrm{p}<0.01]$ than that of the crying babies $(\mathrm{p}<0.01)$ and the circles $(\mathrm{p}<0.05)$. By one-way ANOVA (stimuli), the number of transferring of boys when viewing smiling babies was significantly larger $[\mathrm{F}=4.0, \mathrm{p}<0.05]$ than that of the crying babies $(\mathrm{p}<0.05)$ and the circles $(\mathrm{p}<0.05)$.

Young adult: The main gender difference by two-way ANOVA (gender $\times$ stimuli) was not significant, but the main stimulus effect was significant $[\mathrm{F}=23.4$, $\mathrm{p}<0.0001]$. The number of transferring of the smiling babies was significantly larger than that of both the crying babies $(\mathrm{p}<0.0001)$ and the circles $(\mathrm{p}<0.0001)$. By one-way ANOVA (stimuli), the number of transferring of women when viewing smiling babies was significantly larger $[\mathrm{F}=10.8, \mathrm{p}<0.0001]$ than that of the crying babies $(\mathrm{p}<0.01)$ and the circles $(\mathrm{p}<0.0001)$. The number of transferring of women when viewing crying babies was significantly larger than that of the circles $(p<0.05)$. The number of transferring of men when viewing smiling babies was significantly larger $[\mathrm{F}=16.3, \mathrm{p}<0.0001]$ than that of the crying babies $(p<0.0001)$ and the circles $(p<0.0001)$. By one-way ANOVA (gender), the number of transferring of men when viewing circles was significantly larger $[\mathrm{F}=5.6$, $\mathrm{p}<0.05$ ] than that of age-matched women.

Older adult: The main gender difference and the main stimulus effects were not significant by two-way ANOVA (gender $\times$ stimuli). By one-way ANOVA (stimuli), the number of transferring of women when viewing smiling babies was significantly larger $[\mathrm{F}=4.8$, $\mathrm{p}<0.05$ ] than that of the crying babies $(\mathrm{p}<0.05)$ and the circles $(\mathrm{p}<0.001)$. By one-way ANOVA (stimuli), the number of transferring of older men when viewing smiling babies was significantly larger $[\mathrm{F}=4.0$, $\mathrm{p}<0.05$ ] than that of the crying babies $(\mathrm{p}<0.05)$ and the circles $(\mathrm{p}<0.01)$.

\section{Left and right fields of screen (Fig. 5)}

Pre puberty: The main gender difference by two-way ANOVA (gender $\times$ side) when viewing the simple circles was not significant, but the main field difference was significant $[\mathrm{F}=10.0, \mathrm{p}<0.01]$. There was no inter-

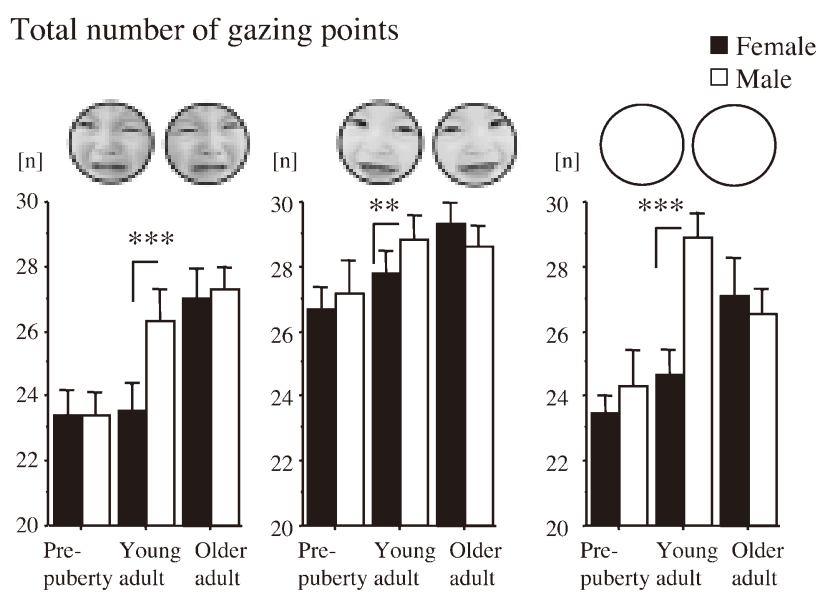

Fig. 4. Total number of gaze points (TNGP; ordinate) while viewing three stimuli, compared between genders and screen fields. Asterisks indicate significant differences between women and the men. $*$ : $\mathrm{p}<0.05$

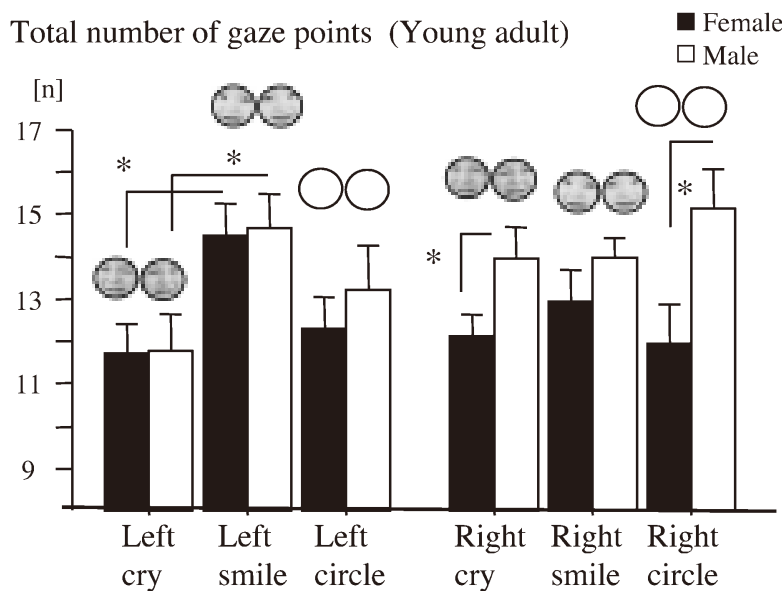

Fig. 5. Total number of gaze points (TNGP; ordinate) while viewing simple circles, compared between genders. Asterisks indicate significant differences between women and the men. *: $\mathrm{p}<0.05$ 
action observed between gender and field. The TNGP in left field was significantly smaller $[p<0.01]$ than those in right field.

Young adult: The main gender difference by two-way ANOVA (gender field) when viewing the crying babies was not significant, but the main field difference was significant $[\mathrm{F}=6.0, \mathrm{p}<0.05]$. There was no interaction observed between gender and group. The TNGP in left field was significantly smaller $(p<0.01)$ than those in right field.

The main gender difference by two-way ANOVA (gender $\times$ field) when viewing the smiling babies was not significant, but the main field difference was significant $[\mathrm{F}=9.0, \mathrm{p}<0.01]$. There was no interaction observed between gender and group. The TNGP in right field was significantly smaller $(p<0.01)$ than those in left field.

The main gender difference by two-way ANOVA (gender $\times$ side) when viewing the circles was significant $[\mathrm{F}=11.3, \mathrm{p}<0.0001]$, but the main side difference was not significant. There was interaction observed between gender and side $(\mathrm{p}<0.05)$. The TNGP [F=6.0, $\mathrm{p}<0.05$ ] of women in right side when viewing crying babies was significant shorter $(\mathrm{p}<0.05)$ than those in age-matched adult men as shown in Fig. 5. The TNGP $[\mathrm{F}=14.6, \mathrm{p}<0.001]$ of women in right side when viewing circles was significant smaller $(\mathrm{p}<0.001)$ than those in age-matched men as shown in Fig. 5.

Older adult: The main gender difference by two-way ANOVA (gender $\times$ side) when viewing the crying babies was not significant but the main side difference was significant $[F=7.9, p<0.01]$. There was no interaction observed between gender and group. The TNGP in left side was significantly smaller $(\mathrm{p}<0.01)$ than those in right side.

\section{DISCUSSION}

The most important finding of the present study was that exploratory eye movements clearly differed between young adult women and men when viewing simple circles and crying babies only at right field, whether pre puberty or older adults did not; this suggests that exploratory eye movement is a useful biologic marker for evaluating the gender difference.

Kojima et al. [2,3] investigated exploratory eye movements using specially constructed S-shaped geometric figures, demonstrating that exploratory eye movement was a useful biologic marker of visual cognitive function in humans. In the present study, we found that exploratory eye movement of women showed properties similar to those previously Miyahira et al. [4] found that TESL in adult women was shorten than that in men. The present study also examined effects of affective stimuli on eye movements as well as gender difference in eye movements at different times of life. Specific aspects are discussed below.

\section{Total eye scanning length (TESL)}

TESL for women was significantly shorter than for men. The TESL when viewing the smiling babies was the longest among the three stimuli, followed by simple circles and then crying babies. Since significant gender differences in TESL were seen only when young adults viewed simple circles, scanning length may vary considerably with age. Young adults, and elderly persons, scanning length varied between agedefined groups for crying babies and simple circles, but not for smiling babies, suggesting that the former figures show more variability in response according to age than the latter. These findings also suggest that simple visual targets may be particularly useful for evaluating exploratory eye movement studies according to gender differences, as reported previously $[4,18]$. Findings might reflect method of visual response assessment, but one should consider that no significant changes among three life phases were seen when viewing the smiling babies.

Before puberty, TESL for crying babies, smiling babies, and circles did not show significant gender differences. In older adults, TESL also did not show significant gender differences. A gender difference for TESL was obtained only in younger adults, suggesting again that responses to these visual stimuli may be developmentally and/or hormonally dependent as reported previously $[4,18]$.

The schismatic decussating of optic nerve fibers from the retina in humans ensures that each primary visual cortex receives input exclusively from the contralateral visual field. The source of gender difference could easily arise from a slightly slower scan [10], a longer decision time at each stage of scanning, or a more rapid decay of stored visual information in women [19].

In young adults, TESL of women on the right side when viewing the simple circles was significantly shorter than that of age-matched adult men, but TESL for the left field did not differ significantly between genders in young adults. In case of the mental rotation task, men showed a right-hemisphere advantage whereas women showed no hemisphere differences $[20,21]$. This laterality may indicate that the gender difference for TESL in adults viewing simple circles resulted from hemispheric functional differences. 
Thus, the TESL on exploratory eye movements may be useful for an evaluation the hemispheric function of brain concerning gender differences.

\section{Total number of gaze points (TNGP)}

The right brain has been considered to role emotional functions, and the left-brain symbolic functions $[14,22]$. In the present study, difference of affective stimuli is obvious only at left fielding the screen, however, gender difference is only observed at right field. Schwartz et al. [20] reported that for emotion-linked images the eyes tended to move leftward, in contrast to rightward for other images; they concluded that this supported links between the right brain and emotional function. Furthermore, Gary et al. [22] reported that right-handed subjects tend to look to the left when answering affective questions, and concluded that the right hemisphere has special role in emotion in the intact brain. We showed that TNGP was smaller when young adult subjects of both genders viewed crying baby faces than when they viewed smiling baby faces, but only in the left field. Thus, the present observations which the effects of affection is significant only at left field on the screen, may be useful for an evaluation the hemispheric function of brain.

Women are considered to show a more cognitive balance between right and left-brain as reported previously $[5,15,23]$.

\section{Conclusions and physiologic significance}

Significant gender differences were observed between young adult women and men when viewing the simple circles and the crying babes evaluation with exploratory eye moving. Shorter TESL and smaller TNGP in adult women were obtained to evaluate fixation points as subjects viewed the simple circles and the crying babies in preparation for copying them. No gender differences were seen in children and older adults, suggesting that exploratory eye movements may be influenced by gonadal hormones [24]. Both TESL and TNGP might be a gender marker, and TNGP might be a reflection of hemispheric function. Women appeared to gaze at certain parts of the circle with even balance between right and left fields, reflecting attentional focus.

Finally, exploratory eye movements while viewing certain pictures showed large differences between women and men in the right field, and marked differences among facial affection in the left field. Thus, exploratory eye movements appear to include gender and hemispheric functional markers helping to make them useful for exploring human visual cognition.

\section{REFERENCES}

1. Holzman PS, Solomon C, Levin S, and Waternaux CS. Pursuit eye movement dysfunction in schizophrenia: Family evidence for specificity. Arch Gen Psychiatry 1984; 41:136-139.

2. Kojima T, Matsushima E, Nakajima K, Shiraishi H, Ando $\mathrm{K}$ et al. Eye movement in acute, chronic, and remit schizophrenics. Biol Psychiatry 1990; 27:975-989.

3. Kojima T, Matsushima E, Ando $\mathrm{K}$, and Ando $\mathrm{H}$. Exploratory eye movement and neuro-psychological tests in schizophrenic patients. Schizophr Bul 1992; 18:85-94.

4. Miyahira A, Morita K, Yamaguchi H, Morita Y, Nonaka K et al. Gender differences of exploratory eye movements: a life span study. Life Science 2000; 68:569-577.

5. Ray WJ, Morell M, Frediani AW, and Tucker DM. Sex differences and lateral specialization of hemispheric functioning. Neuropsychologia 1976; 14:391-394.

6. Buchsbaum MS, Henkin RI, and Christiansen RL. Age and sex differences in averaged evoked responses in a normal population, with observation on patients with gonadal dysgenesis. Electro encephalogr Clin Neurophysiol 1974; 37:137-144.

7. David WL, and Charles SR. Sex differences in cognitive/ motor overload in reaction time tasks. Neuropsychologia 1978; 16:611-616.

8. Delacoste UC, and Holloway RL. Sexual dimorphism in the human corpus callosum. Science 1982; 216:1413-1432.

9. Sheare DE, Emmerson RY, and Dustman RE. Gender differences in pattern reversal evoked potential amplitude; Influence of check size and single tarial response variability. Am J EEG Technol 1992; 32:196-203.

10. Efron R, Yund EW, and Nichols DR. Scanning the visual field without eye movements-A sex difference. Neurosychologia 1987; 125:617-644.

11. Cohn NB, Kircher J, Emmerson RY, and Dustman RE. Pattern reversal evoked potentials: Age, sex and hemispheric asymmetry. Electroencephalogr Clin Neurophysiol 1985; 62:399-405.

12. McGlone J. Sex differences in functional brain asymmetry. Cortex 1978; 14:122-128.

13. Yamamoto M, Morita K, Waseda Y, Ueno T, and Maeda H. Changes in auditory p300 with clinical remission in schizophrenia; Effects of facial-affect stimuli. Psychiatry Clin Neuroscience 2001; 55:347-352.

14. Diamond M, Diamond AL, and Mast M. Visual sensitivity and sexual arousal levels during the menstrual cycles. J Nerv Ment Dis 1972; 155:170-176.

15. Tucker DM. Sex differences in hemispheric specialization for synthetic visuospatial function. Neuropsychologia 1976; 14:447-454.

16. Lang SF, Nelson CA, and Collins PF. Event-related potentials to emotional and neutral stimuli. J Clin Exp Neuropsychol 1990; 12:946-958.

17. Kojima T. A study of eye movements in patients with endogenous depression in comparison with chronic schizophrenics, neurotics and normal subjects. Seishin 1972; 74:511-535. (in Japanese)

18. Miyahira A, Morita K, Yamaguchi H, Morita Y, and Hisao M. Gender differences and reproducibility in exploratory 
eye movements of normal subjects. Psychiatry Clin Neurosci 2000; 54:31-36.

19. Bakan P, and Utnam W. Right-left discrimination and brain materialization: sex differences. Arch Neurol 1974; 30: 334-335.

20. Schwartz GE, Davidson RJ, and Maer F. Right hemisphere lateralization for emotion in the human brain: uneractions with cognition. Science 1975; 190:286-288.

21. Siegel-Hinson RL, and McKeever WF. Hemisphreic specialization, spatial activity experience, and sex differences on tests of mental rotation ability. Laterality 2002; 7:59-74.

22. Gary ES, Richard JD, Foster M, Right hemisphere lateralization for emotion in the human brain: Interaction with cognition. Science 1975; 190:286-288.

23. Rilea SL, Roskos-Ewoldsen B, and Boles D. Sex differences in spatial ability: A lateralization of function approach. Brain Cogn 2004; 56:332-343.

24. Dimond SJ, Farrington L, and Johnson P. Differing emotional response from right and left hemispheric. Nature 1976; 261:690-692. 